Document downloaded from:

http://hdl.handle.net/10251/151279

This paper must be cited as:

Yamaji, M.; Suwa, Y.; Shimokawa, R.; Paris, C.; Miranda Alonso, MA. (2015).

Photochemical reactions of halogenated aromatic 1,3-diketones in solution studied by steady state, one- and two-color laser flash photolyses. Photochemical \& Photobiological Sciences. 14(9):1673-1684. https://doi.org/10.1039/c5pp00211g

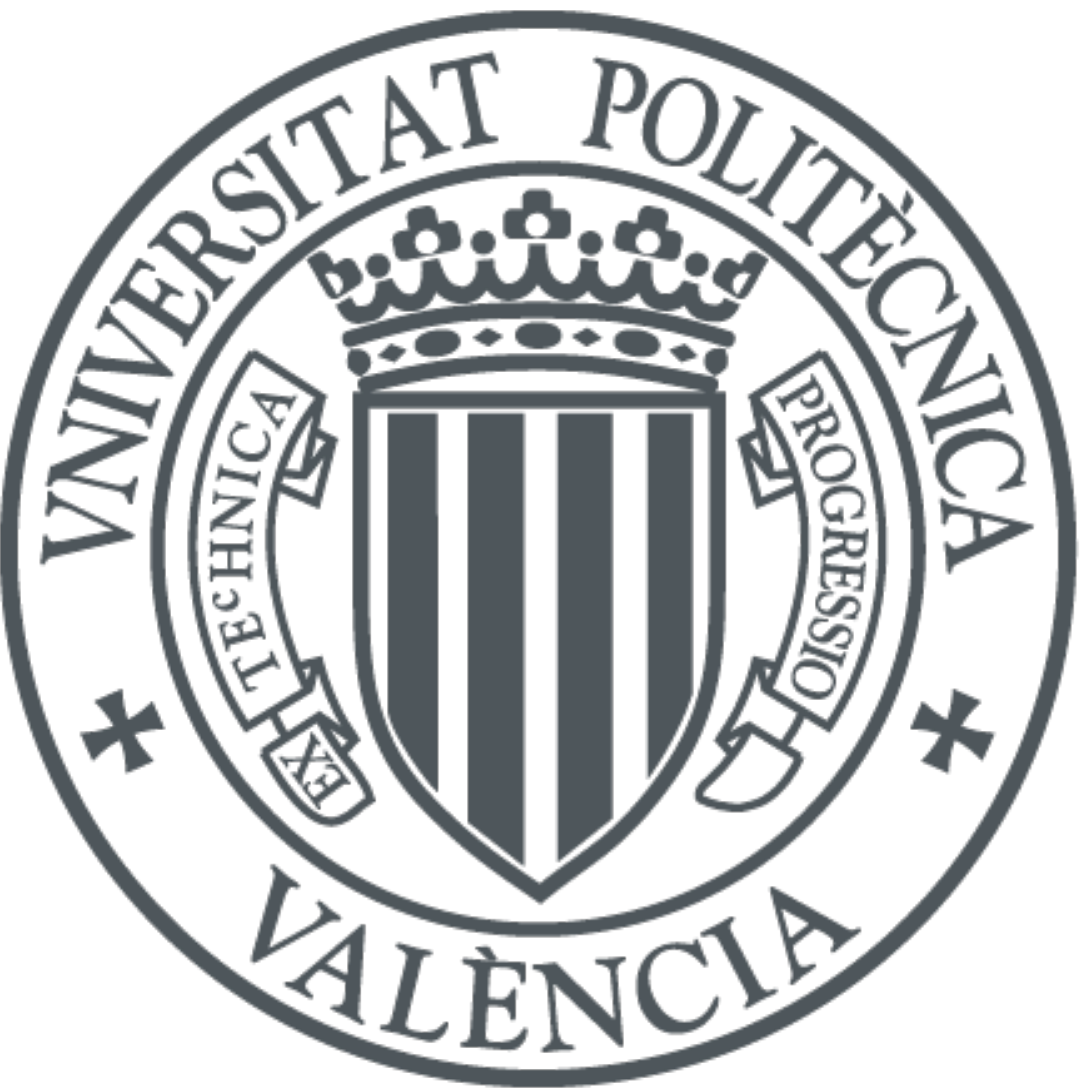

The final publication is available at

https://doi.org/10.1039/c5pp00211g

Copyright The Royal Society of Chemistry

Additional Information 


\section{Photochemical reactions of halogenated aromatic 1,3-diketones in solution studied by steady state, one- and two-color laser flash photolyses}

Minoru Yamaji, ${ }^{\mathrm{a}, *}$ Yurie Suwa, ${ }^{\mathrm{b}}$ Rieko Shimokawa, ${ }^{\mathrm{b}}$ Cecilia Paris ${ }^{\mathrm{c}}$ and Miguel Ángel Miranda ${ }^{\mathrm{c}, *}$

a Division of Molecular Science, Graduate School of Science and Technology, Gunma University, Kiryu, Gunma 376-8515, Japan

${ }^{b}$ Education Program of Materials and Bioscience, Graduate School of Science and Engineering, Gunma University, Kiryu, Gunma 376-8515, Japan

${ }^{c}$ Instituto de Tecnologia Química UPV-CSIC, Universidad Politécnica de Valencia, Valencia, Spain

\section{Contents}

1.Preparation and NMR data for BrPB@Ph, CIPB@Ph, PB@F, PB@T, BrPB@F, BrPB@T, CIPB@F and CIPB@T

2. Absorption and emission spectra of PB@F, PB@T and the halogenated compounds

3. Photochemical features studied by absorption spectrum measurements

4. Determining $\Phi_{\mathrm{AB}}$ by using laser photolysis techniques

5. Transient absorption measurements by $308 \mathrm{~nm}$ laser flash photolysis

6. Dechlorination in a higher triplet state studied by two-color two-laser photolysis

7. DFT calculation for heat of formation and the schematic configurations of the radicals 


\section{Preparation and NMR data for BrPB@Ph, CIPB@Ph, PB@F, PB@T, BrPB@F, BrPB@T, CIPB@F and CIPB@T}

\section{1-1. Preparation of BrPB@Ph}

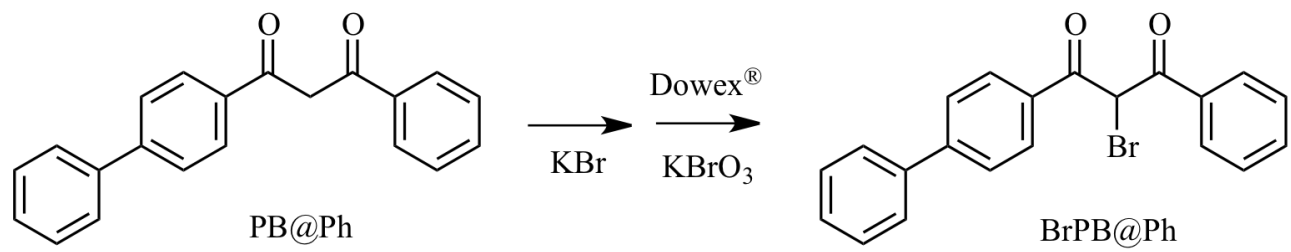

1-Biphenyl-4-yl-3-phenyl-propane-1,3-dione (PB@Ph, 210 mg, 0.7 mmol), KBr (83.3 mg, 0.7 mmol), Dowex ${ }^{\circledR} 1.4 \mathrm{~g}$ were added to $\mathrm{MeOH}(10 \mathrm{ml})$, and the solution was stirred at $0{ }^{\circ} \mathrm{C}$ for 10 min. After adding $\mathrm{KBrO}_{3}(117 \mathrm{mg}, 0.7 \mathrm{mmol})$, the solution was stirred at $0{ }^{\circ} \mathrm{C}$ for $30 \mathrm{~min}$. The products were extracted with benzene $(100 \mathrm{ml})$, the solution was washed with brine, dried with $\mathrm{Na}_{2} \mathrm{SO}_{4}$, and evaporated in vacuum. The product was separated using silica gel column chromatography with hexane/ethyl acetate $(3: 1, \mathrm{v} / \mathrm{v})$ as the eluent, showing a spot on TLC at $\mathrm{Rf}=$ 0.37, providing $130 \mathrm{mg} \mathrm{BrPB} @ \mathrm{Ph}$. Yield $49 \%$. ${ }^{1} \mathrm{H}$ NMR $\left(\mathrm{CDCl}_{3}, 400 \mathrm{MHz}\right) \delta_{\mathrm{H}} 8.06(\mathrm{~d}, 2 \mathrm{H}, J=$ $8.70), 8.00$ (d, 2H, $J=7.10), 7.68$ (d, 2H, $J=8.70), 7.60$ (d, $2 \mathrm{H}, J=8.24), 7.51-7.40$ (m, $6 \mathrm{H})$, $6.56(\mathrm{~s}, 1 \mathrm{H})$. The obtained NMR data are consistent with those in the literature. ${ }^{1}$

\subsection{Preparation of CIPB@Ph}

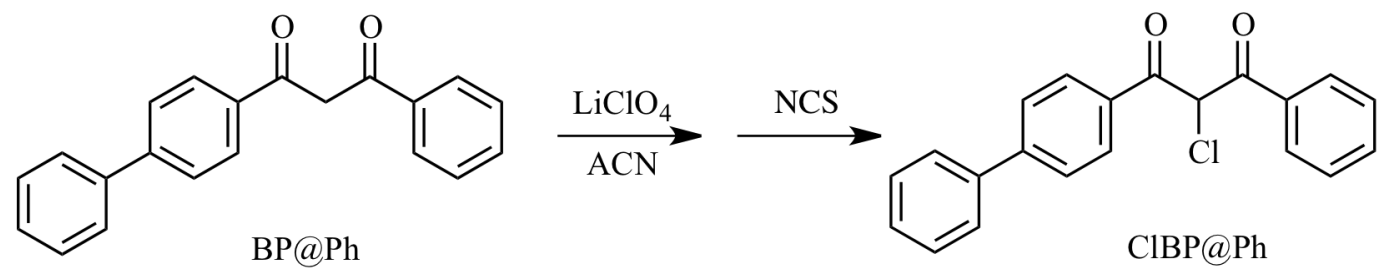

PB@Ph (600 mg, $2 \mathrm{mmol})$ and $\mathrm{LiClO}_{4}(130 \mathrm{mg}, 1.22 \mathrm{mmol})$ were added to acetonitrile $(25 \mathrm{ml})$, and the solution was stirred at room temperature for $10 \mathrm{~min}$. After adding $N$-chlorosuccinimide (NCS, $294 \mathrm{mg}, 2.2 \mathrm{mmol}$ ), the solution was stirred at room temperature for $3 \mathrm{~h}$. After the solvent was evaporated, benzene $(100 \mathrm{ml})$ was added. The solution was washed with brine, dried with $\mathrm{Na}_{2} \mathrm{SO}_{4}$, and evaporated in vacuum. The product was separated using silica gel column chromatography with hexane/ethyl acetate $(9: 1, \mathrm{v} / \mathrm{v})$ as the eluent, showing a spot on TLC at $\mathrm{Rf}=$ 0.17. Recrystallization from hexane provided purified $430 \mathrm{mg}$ ClPB@Ph. Yield 64 \%. ${ }^{1} \mathrm{H}$ NMR $\left(\mathrm{CDCl}_{3}, 400 \mathrm{MHz}\right) \delta_{\mathrm{H}} 8.07(\mathrm{~d}, 2 \mathrm{H}, J=8.70), 8.01(\mathrm{~d}, 2 \mathrm{H}, J=7.33), 7.68(\mathrm{~d}, 2 \mathrm{H}, J=8.47), 7.59$ $(\mathrm{d}, 2 \mathrm{H}, J=7.79), 7.51-7.37(\mathrm{~m}, 6 \mathrm{H}), 6.42(\mathrm{~s}, 1 \mathrm{H})$. 


\subsection{Preparation of $\mathrm{PB} @ \mathrm{~F}$}

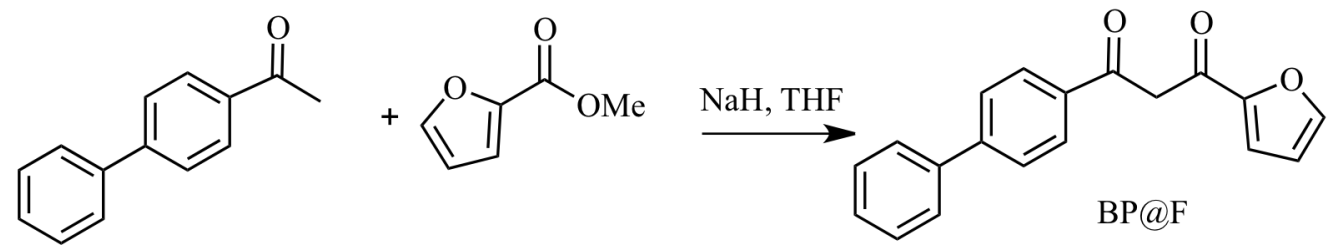

To suspended NaH (600 mg) in dry THF (5 ml), 4-acetylbiphenyl (294 mg, $1.5 \mathrm{mmol})$ was added, and the solution was stirred for $3 \mathrm{~min}$. The solution added with methyl 2 -furorate $(0.21 \mathrm{ml}$, $1.65 \mathrm{mmol}$ ) was refluxed for $24 \mathrm{~h}$, and aqueous $\mathrm{NH}_{4} \mathrm{Cl}$ was added. The product was extracted with ethyl acetate, washed with brine, and the solvent was evaporated in vacuum. The product was separated using silica-gel column chromatography with hexane/ethyl acetate $(9: 1, \mathrm{v} / \mathrm{v})$ as the eluent, showing a spot on TLC at Rf $=0.29$, providing $150 \mathrm{mg}$ PB@F. Yield $34 \%$. ${ }^{1} \mathrm{H}$ NMR $\left(\mathrm{CDCl}_{3}, 400 \mathrm{MHz}\right) \delta_{\mathrm{H}} 8.03(\mathrm{~d}, 2 \mathrm{H}, J=8.70), 7.70(\mathrm{~d}, 2 \mathrm{H}, J=8.47), 7.65-7.59(\mathrm{~m}, 3 \mathrm{H}), 7.51-7.37$ $(\mathrm{m}, 3 \mathrm{H}), 7.26(\mathrm{~d}, 2 \mathrm{H}, J=3.43), 6.80(\mathrm{~s}, 1 \mathrm{H}), 6.59(\mathrm{dd}, 1 \mathrm{H}, J=1.83,3.43)$.

\section{4 preparation of $\mathrm{PB} @ \mathrm{~T}$}<smiles>CCOC(=O)c1cc[Z8](CC(C)C)cc1</smiles>

To suspended $\mathrm{NaH}(600 \mathrm{mg})$ in dry THF (5 ml), 4-acetylbiphenyl (294 mg, $1.5 \mathrm{mmol})$ was added, and the solution was stirred for $3 \mathrm{~min}$. The solution added with methyl thiophene-2-carboxylic acid ethyl ester $(0.26 \mathrm{ml}, 1.65 \mathrm{mmol})$ was refluxed for $24 \mathrm{~h}$, and aqueous $\mathrm{NH}_{4} \mathrm{Cl}$ was added. The product was extracted with ethyl acetate, washed with brine, and the solvent was evaporated in vacuum. The product was separated using silica gel column chromatography with hexane/ethyl acetate $(9: 1, \mathrm{v} / \mathrm{v})$ as the eluent, showing a spot on TLC at $\mathrm{Rf}=$ 0.32, providing $350 \mathrm{mg} \mathrm{PB} @ \mathrm{~T}$. Yield $76 \%{ }^{1} \mathrm{H} \mathrm{NMR}\left(\mathrm{CDCl}_{3}, 400 \mathrm{MHz}\right) \delta_{\mathrm{H}} 8.02(\mathrm{~d}, 2 \mathrm{H}, J=$ 8.47), $7.82(\mathrm{~d}, 1 \mathrm{H}, J=3.66), 7.70(\mathrm{~d}, 2 \mathrm{H}, J=8.47), 7.66-7.61(\mathrm{~m}, 3 \mathrm{H}), 7.51-7.38(\mathrm{~m}, 4 \mathrm{H}), 7.18$ $(\mathrm{dd}, 1 \mathrm{H}, J=3.89,4.81), 6.72(\mathrm{~s}, 1 \mathrm{H})$.

\section{1-5. Preparation of BrPB@F}<smiles>O=C(CC(=O)c1ccco1)c1ccc(-c2ccccc2)cc1</smiles>

PB@F

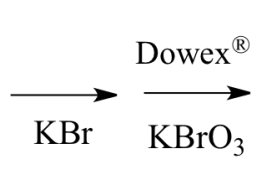<smiles>Brc1ccccc1</smiles>

$\mathrm{BrPB} @ \mathrm{~F}$

1-Biphenyl-4-yl-3-furan-2-yl-propane-1,3-dione (PB@F, 290 mg, 1 mmol), KBr (119 mg, 1 mmol) and Dowex ${ }^{\circledR}(2 \mathrm{~g})$ were added to methanol $(15 \mathrm{ml})$, and the solution was stirred at $0{ }^{\circ} \mathrm{C}$ 
for10 min. After adding $\mathrm{KBrO}_{3}(167 \mathrm{mg}, 1 \mathrm{mmol})$, the solution was stirred at $0{ }^{\circ} \mathrm{C}$ for $30 \mathrm{~min}$. The products were extracted with benzene $(100 \mathrm{ml})$, the solution was washed with brine, dried with $\mathrm{Na}_{2} \mathrm{SO}_{4}$, and evaporated in vacuum. The product was separated using silica gel column chromatography with hexane/ethyl acetate $(3: 1, \mathrm{v} / \mathrm{v})$ as the eluent, showing a spot on TLC at $\mathrm{Rf}=$ 0.28 , providing $230 \mathrm{mg}$ BrPB@F. Yield $62 \% .{ }^{1} \mathrm{H} \mathrm{NMR}\left(\mathrm{CDCl}_{3}, 400 \mathrm{MHz}\right) \delta_{\mathrm{H}} 8.09(\mathrm{~d}, 2 \mathrm{H}, J=$ 8.70), 7.70 (d, $2 \mathrm{H}, J=8.70), 7.62-7.59$ (m, 3H), 7.51-7.39 (m, 4H), 6.58 (dd, $1 \mathrm{H}, J=1.83,3.66)$, $6.41(\mathrm{~s}, 1 \mathrm{H})$. The obtained data are consistent with those in the literature. ${ }^{1}$

\section{1-6. Preparation of BrPB@T}<smiles>O=C(CC(=O)c1cccs1)c1ccc(-c2ccccc2)cc1</smiles>

1-Biphenyl-4-yl-3-thiophen-2-yl-propane-1,3-dione (PB@T, 306 mg, 1 mmol), KBr (119 mg, 1 mmol) and Dowex ${ }^{\circledR}(2 \mathrm{~g})$ were added to methanol $(15 \mathrm{ml})$, and the solution was stirred at $0{ }^{\circ} \mathrm{C}$ for $10 \mathrm{~min}$. After adding $\mathrm{KBrO}_{3}(167 \mathrm{mg}, 1 \mathrm{mmol})$, the solution was stirred at $0{ }^{\circ} \mathrm{C}$ for $30 \mathrm{~min}$. The products were extracted with benzene $(100 \mathrm{ml})$, the solution was washed with brine, dried with $\mathrm{Na}_{2} \mathrm{SO}_{4}$, and evaporated in vacuum. The product was separated using silica gel column chromatography with hexane/ethyl acetate $(3: 1, \mathrm{v} / \mathrm{v})$ as the eluent, providing $160 \mathrm{mg} \mathrm{BrPB} @ \mathrm{~T}$. Yield $42 \%$. ${ }^{1} \mathrm{H}$ NMR $\left(\mathrm{CDCl}_{3}, 400 \mathrm{MHz}\right) \delta_{\mathrm{H}} 8.10(\mathrm{~d}, 2 \mathrm{H}, J=8.47), 7.87(\mathrm{dd}, 1 \mathrm{H}, J=1.14,3.89)$, 7.72-7.67 (m, 3H), $7.60(\mathrm{~d}, 2 \mathrm{H}, J=6.89), 7.51-7.37(\mathrm{~m}, 3 \mathrm{H}), 7.13(\mathrm{dd}, 1 \mathrm{H}, J=3.89,5.04), 6.34$ $(\mathrm{s}, 1 \mathrm{H})$.

\section{1-7. Preparation of CIPB@F}<smiles>O=C(CC(=O)c1ccc(-c2ccc(C(=O)N3CCCC3)cc2)o1)c1ccc(-c2ccccc2)cc1</smiles>

1-Biphenyl-4-yl-3-furan-2-yl-propane-1,3-dione (PB@F, $435 \mathrm{mg}, 1.5 \mathrm{mmol})$ and $\mathrm{LiClO}_{4}(98 \mathrm{mg}$, $0.9 \mathrm{mmol})$ were added to acetonitrile $(20 \mathrm{ml})$, and the solution was stirred at room temperature for $10 \mathrm{~min}$. After adding NCS (221 mg, $1.7 \mathrm{mmol})$, the solution was stirred at room temperature for $4 \mathrm{~h}$. After the solvent was evaporated, benzene $(100 \mathrm{ml})$ was added. The solution was washed with brine, dried with $\mathrm{Na}_{2} \mathrm{SO}_{4}$, and evaporated in vacuum. The product was separated using silica-gel column chromatography with hexane/ethyl acetate $(3: 1, \mathrm{v} / \mathrm{v})$ as the eluent, showing a spot on TLC at Rf $=0.29$, providing $270 \mathrm{mg}$ ClPB@F. Yield $55 \%$. ${ }^{1} \mathrm{H} \mathrm{NMR}\left(\mathrm{CDCl}_{3}, 400 \mathrm{MHz}\right)$ 
$\delta_{\mathrm{H}} 8.10(\mathrm{~d}, 2 \mathrm{H}, J=8.5), 7.70(\mathrm{~d}, 2 \mathrm{H}, J=8.5), 7.62-7.58(\mathrm{~m}, 3 \mathrm{H}), 7.51-7.39(\mathrm{~m}, 4 \mathrm{H}), 6.58(\mathrm{dd}$, $1 \mathrm{H}, J=1.6,3.7), 6.28(\mathrm{~s}, 1 \mathrm{H})$.

\section{1-8. Preparation of CIPB@T}

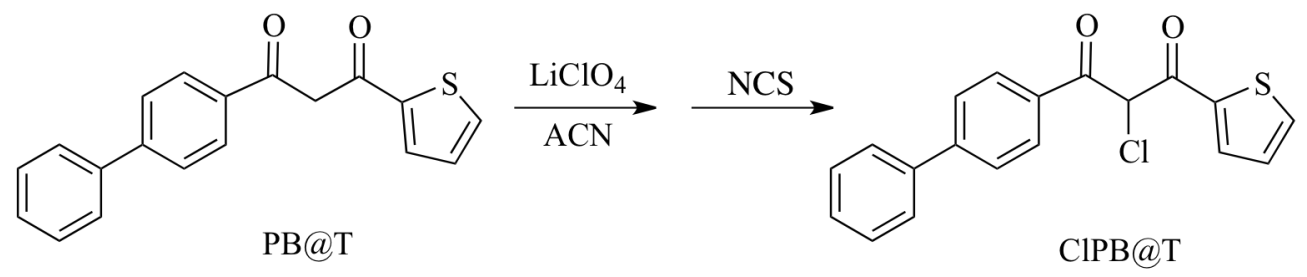

1-Biphenyl-4-yl-3-thiophen-2-yl-propane-1,3-dione (PB@T, 306 mg, 1.0 mmol) and $\mathrm{LiClO}_{4}(65$ $\mathrm{mg}, 0.61 \mathrm{mmol})$ were added to acetonitrile $(20 \mathrm{ml})$, and the solution was stirred at room temperature for $10 \mathrm{~min}$. After adding $N$-chlorosuccinimide (NCS, $65 \mathrm{mg}, 0.6 \mathrm{mmol}$ ), the solution was stirred at room temperature for $4 \mathrm{~h}$. After the solvent was evaporated, benzene $(100 \mathrm{ml})$ was added. The solution was washed with brine, dried with $\mathrm{Na}_{2} \mathrm{SO}_{4}$, and evaporated in vacuum. The product was separated using silica gel column chromatography with hexane/ethyl acetate $(3: 1$, $\mathrm{v} / \mathrm{v}$ ) as the eluent, showing a spot on TLC at Rf=0.43, providing $341 \mathrm{mg}$ ClPB@T. Yield $44 \%$. ${ }^{1} \mathrm{H} \mathrm{NMR}\left(\mathrm{CDCl}_{3}, 400 \mathrm{MHz}\right) \delta_{\mathrm{H}} 8.11(\mathrm{~d}, 2 \mathrm{H}, J=8.47), 7.92(\mathrm{~d}, 1 \mathrm{H}, J=3.89), 7.72(\mathrm{~d}, 1 \mathrm{H}, J=$ 4.81), $7.68(\mathrm{~d}, 2 \mathrm{H}, J=8.47), 7.60(\mathrm{~d}, 2 \mathrm{H}, J=7.56), 7.48-7.38(\mathrm{~m}, 3 \mathrm{H}), 7.14(\mathrm{dd}, 1 \mathrm{H}, J=4.12$, 4.81), $6.22(\mathrm{~s}, 1 \mathrm{H})$.

\section{Absorption and emission spectra of PB@F,PB@T and the halogenated diketones}

Figure S1 shows absorption and emission spectra of $\mathrm{PB} @ \mathrm{~F}, \mathrm{~PB} @ \mathrm{~T}$ and the halogenated compounds in solution. From the wavelength regions of the absorption maxima, the molecular configurations of these compounds are inferred.PB@F and PB@T are in the enol form while the other halogenated diketones are in the keto form. 

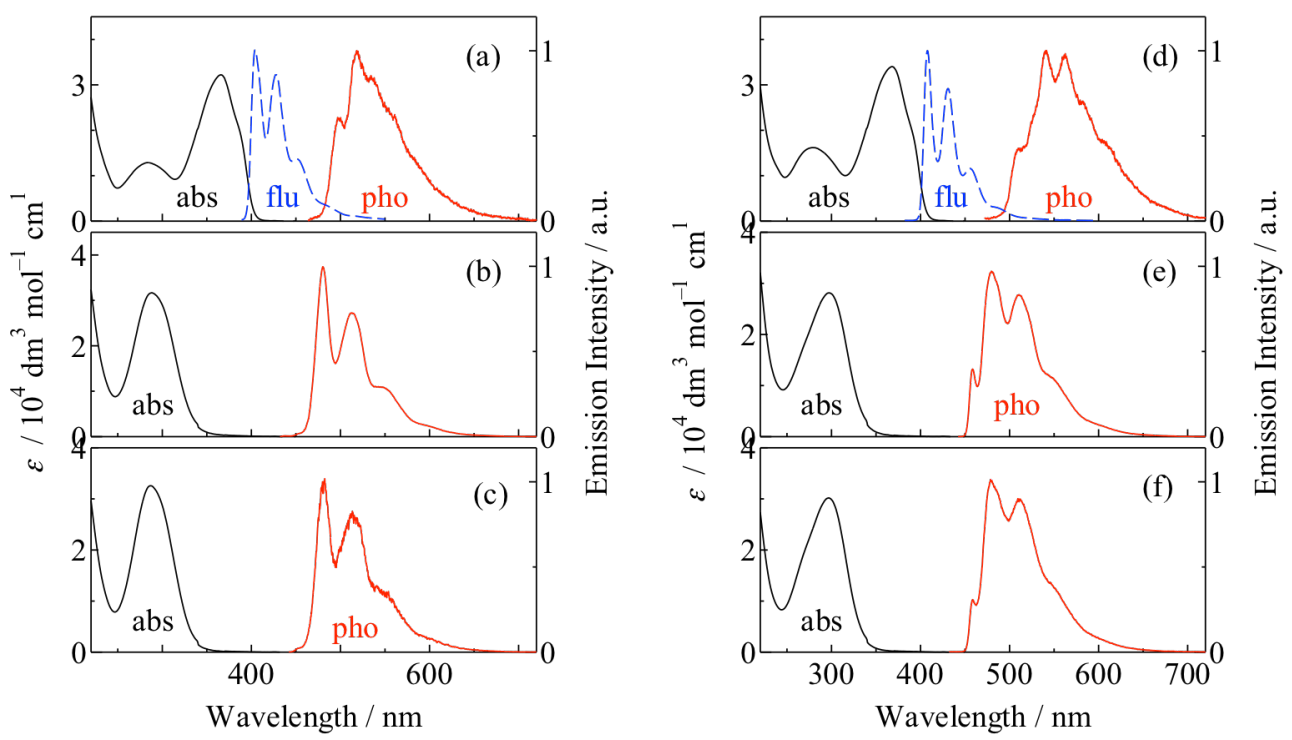

Figure S1. Absorption spectra (solid) in $\mathrm{ACN}$ at $295 \mathrm{~K}$ and phosphorescence spectra (red) in EtOH at 77 K for PB@F (a),BrPB@F (b), ClPB@F (c), PB@T (d),BrPB@T (e) and ClPB@T (f). Fluorescence (blue) was observed for PB@F (a) and PB@T (d) in EtOH at 77 $\mathrm{K}$ whereas that from BrPB@F, ClPB@F, BrPB@T and ClPB@T was not observed at $295 \mathrm{~K}$ and $77 \mathrm{~K}$.

\section{Photochemical features studied by absorption spectrum measurements}

\subsection{Absorption spectrum measurements of $B r P B @ F$ and $B r P B @ T$ upon stationary photolysis}

Figures S2 and 3 show absorption spectral changes upon photolysis of BrPB@F and BrPB@T in EtOH and $\mathrm{CH}$, respectively. Absorption spectrum of $\mathrm{BrPB} @ \mathrm{~F}$ in $\mathrm{EtOH}$ consists of that for the keto form at $280 \mathrm{~nm}$ and probably that for the enol form of BrPB@F at $378 \mathrm{~nm}$ (Figure S2a). BrPB@F showed absorption spectral changes without isosbestic points upon photolysis in EtOH, providing an absorption band at 360 nm due to PB@F. Consequently, photolysis of BrPB@F in EtOH provides $\mathrm{PB} @ \mathrm{~F}$ via debromination in the $\mathrm{S}_{1}$ state. Conversely, BrPB@T decomposed and gave rise to the absorption band of $\mathrm{PB} @ \mathrm{~T}$ with isosbestic points (Figure $\mathrm{S} 2 \mathrm{~b}$ ). The fact of forming PB@T demonstrates occurrence of photodebromination from BrPB@T in EtOH. The quantum yield for the $\mathrm{PB} @ \mathrm{~T}$ formation was determined to be $0.10 \pm 0.01$, which was independent of the amount of the dissolved oxygen. The photodebromination of BrPB@T in EtOH also proceeds in the $\mathrm{S}_{1}$ state.

In $\mathrm{CH}$, as increasing the irradiation time, BrPB@F and BrPB@T decompose with isosbestic points, providing absorption shoulders at $350 \mathrm{~nm}$, which are different from the absorption bands of the corresponding dehalogenated compounds (Figure S3). We were unable to identify the photoproducts due to the absorption shoulders at $350 \mathrm{~nm}$ from the final absorption spectra. 


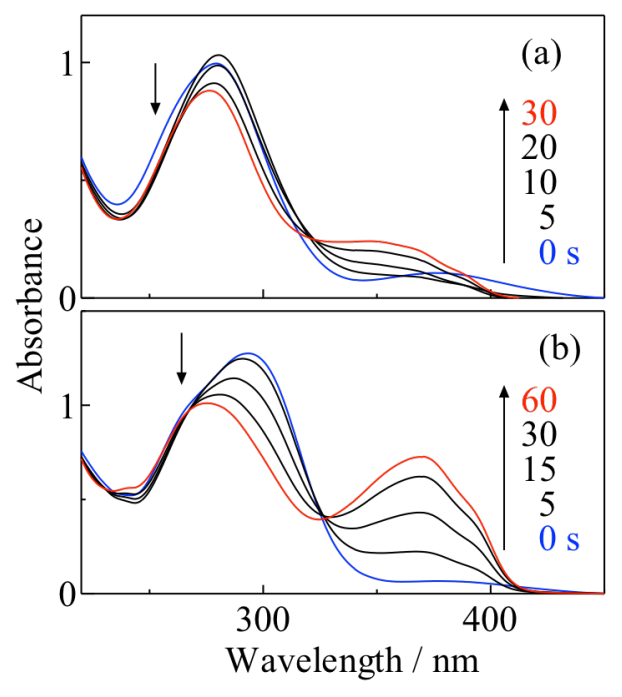

Figure. S2 Absorption spectral changes upon photolysis $(\lambda>280 \mathrm{~nm})$ of $\mathrm{BrPB} @ \mathrm{~F}$ and BrPB@T in EtOH.

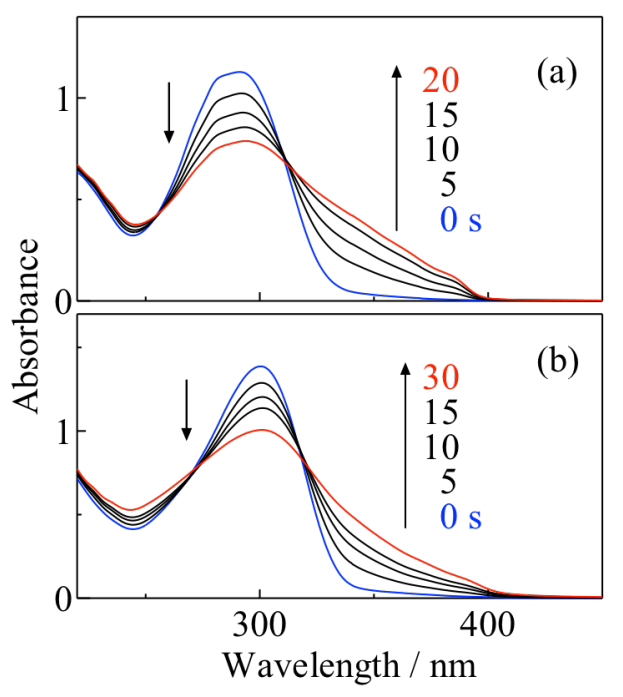

Figure. S3 Absorption spectral changes upon photolysis $(\lambda>280 \mathrm{~nm})$ of $\mathrm{BrPB} @ \mathrm{~F}$ and BrPB@T in $\mathrm{CH}$.

\subsection{Photolysis of $p$-methoxyphenacyl chloride and $p$-tert-butylbenzaldehyde in aerated ACN}

Figure S4 shows absorption spectral changes upon $254 \mathrm{~nm}$ photolysis of $p$-methoxyphenacyl chloride in aerated ACN. As increasing the irradiation time, the absorbance at $275 \mathrm{~nm}$ decreased, giving an absorption spectrum having the maximum at $220 \mathrm{~nm}$ at $300 \mathrm{~s}\left(\mathrm{PP}_{220}\right)$. On the other hand, photolysis of $p$-tert-butylbenzaldehyde in aerated ACN gave no changes in the absorption spectrum.

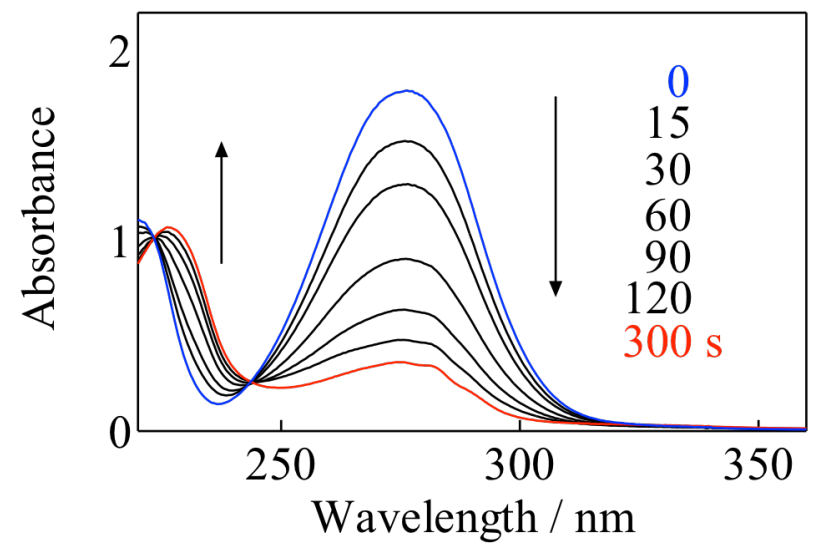

Figure S4. Absorption spectral changes upon $254 \mathrm{~nm}$ photolysis of $p$-methoxyphenacyl chloride in aerated ACN.

\subsection{Photolysis of $p$-phenylphenacyl chloride and benzaldehyde in aerated ACN}

Figure S5 shows absorption spectral changes upon $254 \mathrm{~nm}$ photolysis of ClPB@Ph and p-phenylphenacyl chloride in aerated $\mathrm{CH}$ and the reference spectra of $\mathrm{PP}_{276}$ and benzaldehyde. As increasing the irradiation time, the absorbance at $295 \mathrm{~nm}$ of CIPB@Ph decreased, giving an absorption spectrum having the maximum at $276 \mathrm{~nm}$ at $360 \mathrm{~s}\left(\mathrm{PP}_{276}\right)$. On the other hand, 
photolysis of p-tert-butylbenzaldehyde in aerated ACN gave no changes in the absorption spectrum $\left(\lambda_{\max }=243 \mathrm{~nm} ; \varepsilon_{243}=14900 \mathrm{dm}^{3} \mathrm{~mol}^{-1} \mathrm{~cm}^{-1}\right.$ in $\left.\mathrm{CH}\right)$.
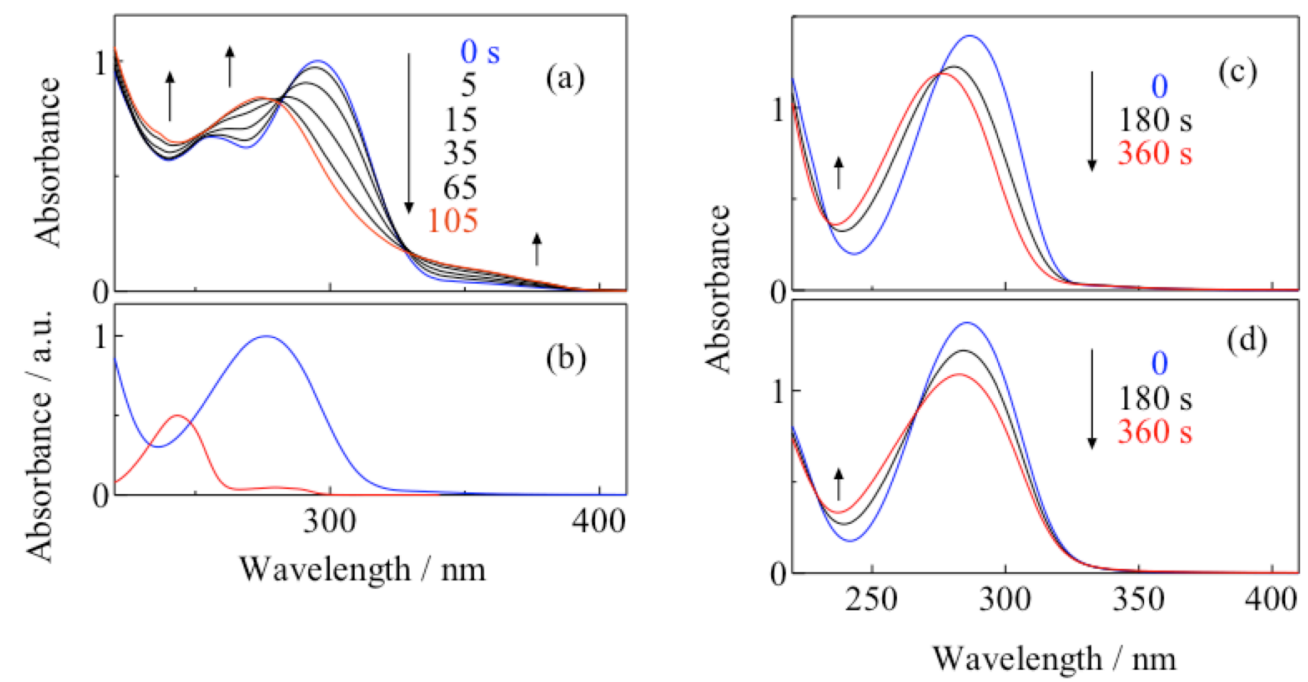

Figure S5. (a) Absorption spectral changes upon photolysis $(\lambda>280 \mathrm{~nm})$ of $\mathrm{ClPB} @ \mathrm{Ph}$ in aerated $\mathrm{CH}$. (b) Reference absorption spectra of $\mathrm{PP}_{276}$ (blue) and benzaldehyde (red). (c) Absorption spectral changes upon photolysis $(\lambda>280 \mathrm{~nm})$ of $p$-phenylphenacyl chloride in aerated $\mathrm{CH}$. (d) Absorption spectral changes upon photolysis $(\lambda>280 \mathrm{~nm})$ of $p$-phenylphenacyl chloride in aerated $\mathrm{CH}$.

\subsection{Absorption spectral changes upon steady state photolysis of CIPB@Ph in ACN and the absorption spectra of the isolated photoproducts}

Figure S6a shows absorption spectral changes upon photolysis of ClPB@Ph in ACN, which have been shown as Figure $4 \mathrm{~b}$ in the text. We were succeeded in isolating the photoproducts $\left(\mathrm{PP}_{253}\right.$ and $\left.\mathrm{PP}_{283}\right)$ having the absorption peaks at $253 \mathrm{~nm}$ and $283 \mathrm{~nm}$ using a home-made microflow photoreactor. The absorption spectra of $\mathrm{PP}_{253}$ and $\mathrm{PP}_{283}$ are shown as Figure $\mathrm{S} 6 \mathrm{~b}$ and c, respectively. Superposing these absorption spectra well reproduced the absorption spectra at $105 \mathrm{~s}$ in Figure S6a. 


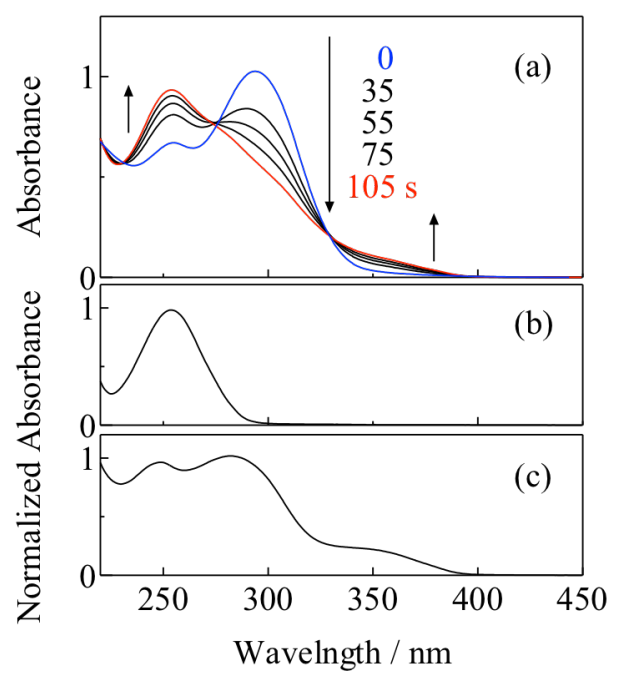

Figure S6. (a) Absorption spectral changes upon photolysis $(\lambda>270 \mathrm{~nm})$ of ClPB@Ph in aerated ACN. Reference absorption spectra of $\mathrm{PP}_{253}$ (b) and $\mathrm{PP}_{283}$ (c) in $\mathrm{ACN}$.

\subsection{Absorption measurements of CIPB@F and CIPB@T upon stationary photolysis}

Figure S7 shows absorption spectral changes upon photolysis of $\mathrm{ClPB} @ \mathrm{~F}$. In $\mathrm{CH}$, as increasing the irradiation time, the absorbance of CIPB@F at $290 \mathrm{~nm}$ decreased whereas an absorption band at 366 nm due to PB@F appeared (Figure S7a). These absorption changes indicate occurrence of dechlorination from $\mathrm{ClPB} @ \mathrm{~F}$, followed by $\mathrm{H}$-atom abstraction from $\mathrm{CH}$ by the produced dechlorinated radical. In ACN, isosbestic poins appear on photodecomposition of $\mathrm{ClPB} @ \mathrm{~F}$, giving a broad absorption band in the wavelength region, 320 - $400 \mathrm{~nm}$ consisted not only of the charactristic absorption band $\left(\lambda_{\max }=366 \mathrm{~nm}\right)$ of PB $@$ F (Figure S7b). $\alpha$-Bond dissociation might be a concomitant reaction. In $\mathrm{EtOH}$ the absorption band for the enol form of $\mathrm{ClPB} @ \mathrm{~F}$ is observed before photorradiation as well as seen for BrClPB@F in EtOH (Figure S2a), but after starting photolysis, absorption changes similar to those in ACN were seen (Figure S7c). We were unable to analyze photochemical reactions of CIPB@F in EtOH. The observed photochemical reactions in these solvents proceeded irrespective of the presence of the dissolved oxygen. Thus, the photodecomposition of CIPB@F is the event in th $\mathrm{S}_{1}$ state. 


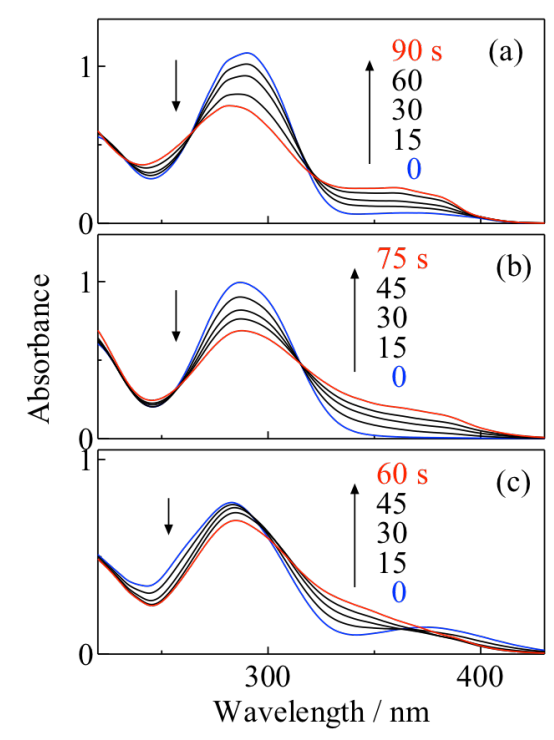

Figure S7. Absorption spectral changes upon photolysis $(\lambda>270 \mathrm{~nm})$ of $\mathrm{ClPB} @ \mathrm{~F}$ in $\mathrm{CH}(\mathrm{a}), \mathrm{ACN}(\mathrm{b})$ and $\mathrm{EtOH}(\mathrm{c})$.

Figure S8 shows absorption spectral changes upon photolysis of $\mathrm{ClPB} @ \mathrm{~T}$ in $\mathrm{CH}$ and $\mathrm{ACN}$. In both the solvents, the absorption band of $\mathrm{ClPB} @ \mathrm{~T}$ diminished with isosbestic points, giving rise to the absorption band due to $\mathrm{PB} @ \mathrm{~T}$ at $360 \mathrm{~nm}$ independent of the amount of the dissolved oxygen. These absorption spectral changes indicate the dechlorination of $\mathrm{ClPB} @ \mathrm{~F}$ in the $\mathrm{S}_{1}$ state.

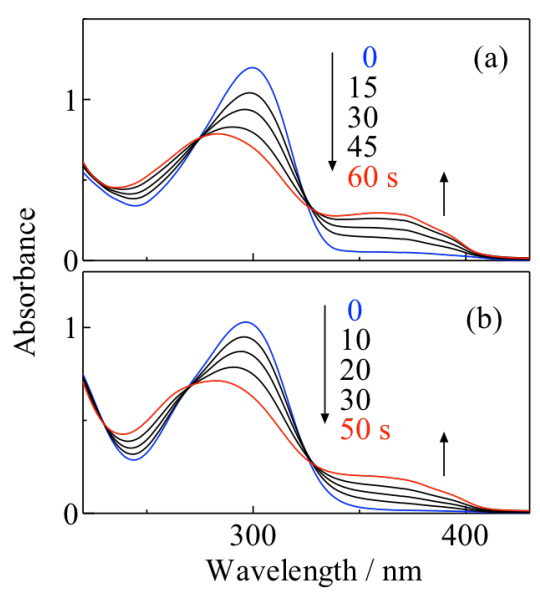

Figure S8. Absorption spectral changes upon photolysis $(\lambda>270 \mathrm{~nm})$ of $\mathrm{ClPB} @ \mathrm{~T}$ in $\mathrm{CH}$ (a) and $\mathrm{ACN}(\mathrm{b})$.

\section{Determining $\Phi_{\mathrm{AB}}$ by using laser photolysis techniques}

Figure $\mathrm{S} 9$ shows absorbance changes, $\Delta A_{\lambda}$ due to the formed species $(\lambda=356 \mathrm{~nm}$ for $\mathrm{AB}$ and $\lambda=$ $343 \mathrm{~nm}$ for MC) obtained upon $266 \mathrm{~nm}$ laser photolysis of BrAB in EtOH and MDPA in MCH plotted as a function of the term, $1-10^{-A_{266}}$. The Plots show straight lines. From the slope to the lines and eqns 1 and 2, the value of $\Phi_{\mathrm{AB}}$ in $\mathrm{EtOH}$ was determined to be $0.07 \pm 0.01$. 


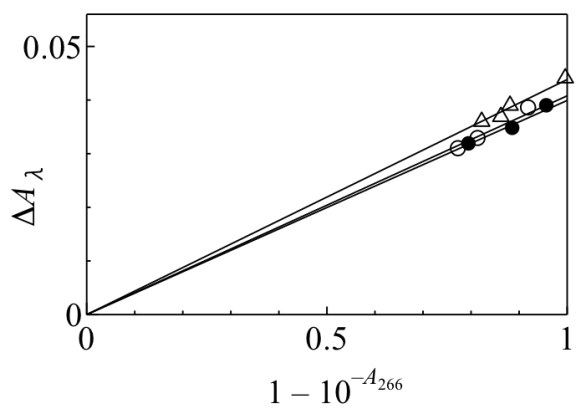

Figure S9. Absorbance changes, $\Delta A_{\lambda}$ at $\lambda \mathrm{nm}$ obtained upon $266 \mathrm{~nm}$ laser photolysis of $\mathrm{BrAB}$ in degassed $\mathrm{EtOH}(0 ; \lambda=356 \mathrm{~nm})$ and aerated $\mathrm{EtOH}(\bullet ; \lambda=356 \mathrm{~nm})$, and of MDPA in aerated $\mathrm{MCH}(\triangle ; \lambda=343 \mathrm{~nm})$ plotted as a function of the term, $1-10^{-A_{266}}$.

\section{Transient absorption measurements by $308 \mathrm{~nm}$ laser flash photolysis}

\subsection{Laser flash photolysis of BrPB@F and BrPB@T}

Figure S10 shows transient absorption spectra of $\mathrm{BrPB} @ \mathrm{~F}$ and $\mathrm{BrPB} @ \mathrm{~T}$ upon $308 \mathrm{~nm}$ laser pulsing in EtOH. Absorption bands at $450 \mathrm{~nm}$ for $\mathrm{BrPB} @ \mathrm{~F}$ and BrPB@T seen at $80 \mathrm{~ns}$ diminished with a decay lifetime of $4.9 \mu \mathrm{s}$, which was shortened in the presence of the dissolved oxygen. The observed absorption bands at $450 \mathrm{nn}$ are ascribable to the T-T absorption of BrPB@F and BrPB@T. As increasing the time, absorption bands at 355 nm for C1PB@F and 265 nm for $\mathrm{ClPB} @ \mathrm{~T}$, which are consistent with those of $\mathrm{PB} @ \mathrm{~F}$ and $\mathrm{PB} @ \mathrm{~T}$, respectively, appeared in the millisecond time domain. The increasing features of the bands were independent of the presence of the dissolved oxygen. From these observations of the transient data, debromination and intersystem crossing to the $\mathrm{T}_{1}$ state are concomitants in the $\mathrm{S}_{1}$ states of BrPB@F andBrPB@T in EtOH. 


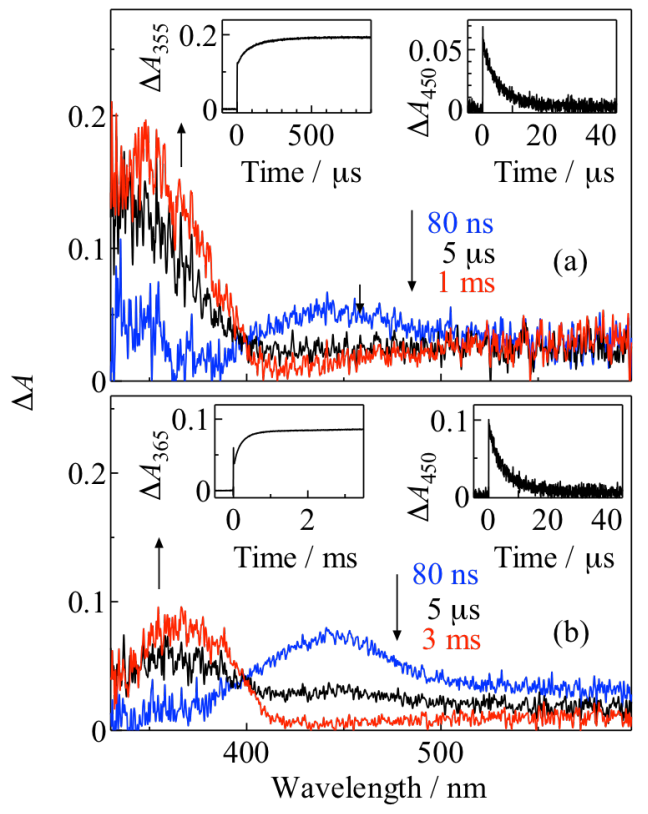

Figure S10. Transient absorption spectra obtained upon $308 \mathrm{~nm}$ laser pulsing in degassed EtOH solution of BrPB@F (a) and BrPB@T (b). Insets; temporal absorbance at $355 \mathrm{~nm}$ (upper, left), $450 \mathrm{~nm}$ (upper, right), $365 \mathrm{~nm}$ (lower, left) and $450 \mathrm{~nm}$ (lower, right).

Figure S11 shows transient absorption spectra of BrPB@F and BrPB@T upon 308 nm laser in $\mathrm{CH}$. At $80 \mathrm{~ns}$ after laser pulsing in the $\mathrm{CH}$ solution, transient absorption bands at $500 \mathrm{~nm}$ for ClPB@F and 453 nm for BrPB@T were observed. The absorbance of these bands decreased with lifetimes of $7.2 \mu$ s for BrPB@F and 5.8 $\mu$ s for BrPB@T. These lifetimes were independent of the presence of the dissolved oxygen. These transient absorption bands are, therefore, not for the triplet manifolds. In the tens microsecond time domain, absorption bands at $337 \mathrm{~nm}$ for ClPB@F and 340 nm for BrPB@T appeared. Absorption maxima of these bands are different from those of the corresponding nonhalogenated enol forms. We have not observed the debromination from these compounds in $\mathrm{CH}$ by steady state photolysis studies. We were unable to identify the chemical reactions of these compounds in $\mathrm{CH}$ from the transient absorption measurements. We can say that the photochemical reactions of BrPB@F and BrPB@T strictly depend on the variety of the solvent. 


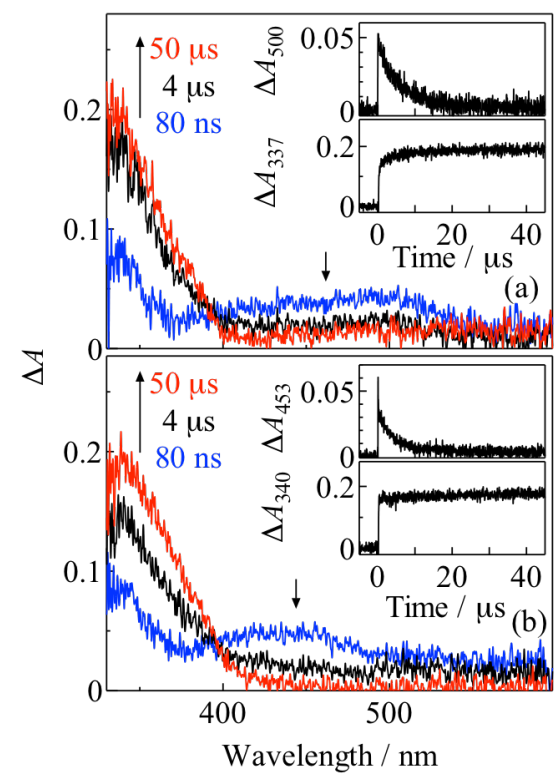

Figure S11. Transient absorption spectra upon $308 \mathrm{~nm}$ laser pulsing in degassed $\mathrm{CH}$ solution of BrPB@F (a) and BrPB@T (b). Insets; temporal absorbance at $500 \mathrm{~nm}$ (upper in (a)), $337 \mathrm{~nm}$ (lower in (b)), $453 \mathrm{~nm}$ (upper in (b)) and $340 \mathrm{~nm}$ (lower in (b)).

\subsection{Laser flash photolysis of CIPB@F and CIPB@T}

Figures S12 and 13, respectively, show transient absorption spectra of ClPB@F and ClPB@T at $80 \mathrm{~ns}$ upon $308 \mathrm{~nm}$ laser pulsing. Transient absorption spectra located in the wavelength region, 440 - $460 \mathrm{~nm}$ have the similar spectral features. The lifetimes of the absorption bands for CIPB@F were 100 ns in CH, 80 ns in ACN and 140 ns in EtOH whereas those for ClPB@T were $260 \mathrm{~ns}$ in $\mathrm{CH}$ and $90 \mathrm{~ns}$ in ACN. Since the lifetimes were shortened in the presence of the dissolved oxygen, the observed transient absorption spectra are due to the triplet states of the corresponding chlorinated diketones. We have recognized that these chlorinated diketones mainly undergo photodechlorination in the $S_{1}$ state. Observation of the triplet state indicates that intersystem crossing from the $S_{1}$ to the $T_{1}$ is efficient in these chlorinated diketones. After depletion of the T-T absorption, no residual absorption was found in the wavelength region longer than $400 \mathrm{~nm}$. 


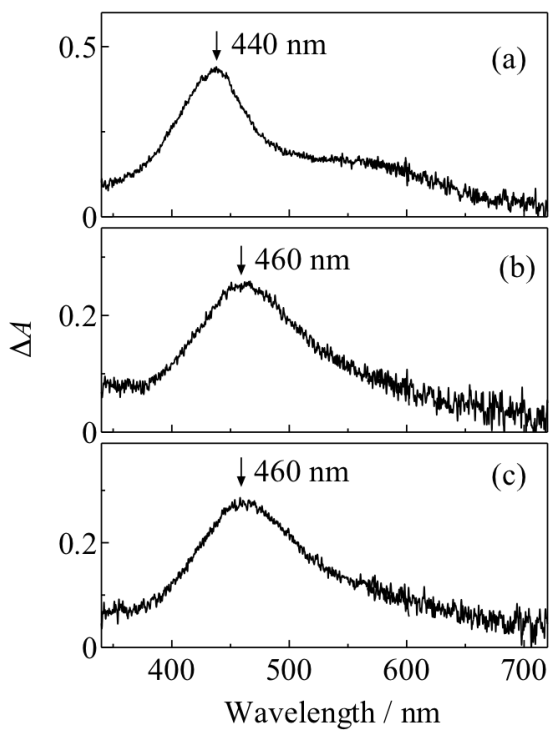

Figure S12. Transient absorption spectra obtained at $80 \mathrm{~ns}$ upon $308 \mathrm{~nm}$ laser pulsing of $\mathrm{ClPB} @ \mathrm{~F}$ in degassed $\mathrm{CH}$ (a), $\mathrm{ACN}(\mathrm{b})$ and $\mathrm{EtOH}(\mathrm{c})$.

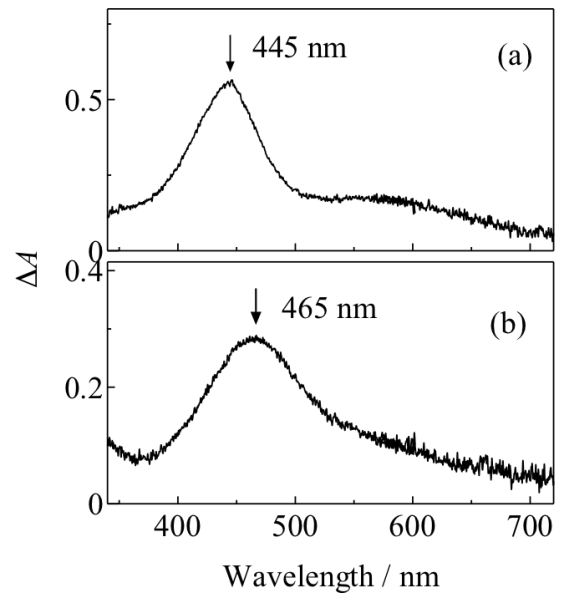

Figure S13. Transient absorption spectra at $80 \mathrm{~ns}$ upon $308 \mathrm{~nm}$ laser pulsing of ClPB@T in degassed CH (a) and $\mathrm{ACN}(\mathrm{b})$.

\section{Dechlorination in a higher triplet state studied by two-color two-laser photolysis}

We have obtained relatively intense T-T absorption of ClPB@F and ClPB@T in CH upon 308 $\mathrm{nm}$ laser photolysis, two-color two-laser photolysis of these compound in $\mathrm{CH}$ was performed. The wavelength of the second laser pulse was adopted $440 \mathrm{~nm}$. The first excitation with a 308 $\mathrm{nm}$ laser pulse produces the triplet absorption that efficiently absorbs the second $440 \mathrm{~nm}$ laser pulse with a $50 \mathrm{~ns}$ delay. The $440 \mathrm{~nm}$ laser pulse is, thus, absorbed only by the triplet. Figures S14 and 15 show absorption spectral changes upon one and two-laser pulsing of ClPB@F and ClPB@T, respectively in CH. As increasing the number of one-color laser pulses, absorption due to the dechlorinated diketones appears at $360 \mathrm{~nm}$. In the presence of the second $440 \mathrm{~nm}$ laser pulse, more intense absorption at 360nm can be recognized in Figure S14b and 15b. In order to make clear the difference in the absorbance, subtraction between the absorption spectra obtained by one and two-color laser pulsing was executed (Figures S14c and 15c). The obtained difference spectra, which agree with those of the nonchlorinated diketones, are originated from the dechlorination upon exciting the $\mathrm{T}_{1}$ states. These results convince that dechlorination unambiguously proceeds in a higher triplet $\left(\mathrm{T}_{\mathrm{n}}\right)$ state. The quantum yields for dechlorination in the $T_{n}$ state were too small to determine by laser photolysis techniques. 


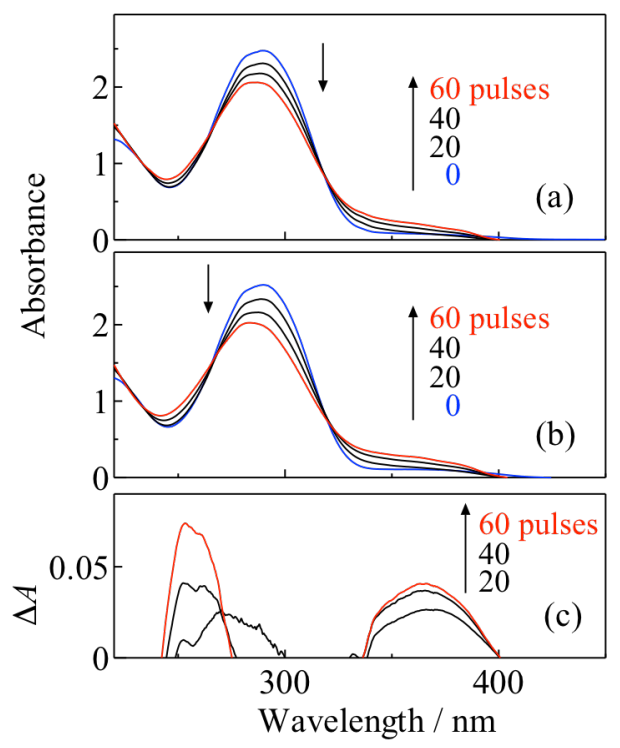

Figure S14. Absorption spectral changes after $308 \mathrm{~nm}$ laser pulsing (a) and $308 \mathrm{~nm}$ plus $50 \mathrm{~ns}$ delayed $440 \mathrm{~nm}$ laser pulsing (b) in the degassed $\mathrm{CH}$ of $\mathrm{ClPB} @ \mathrm{~F}$. (c) Difference absorption spectra between ones in (a) and (b) at the corresponding number of the laser pulses.

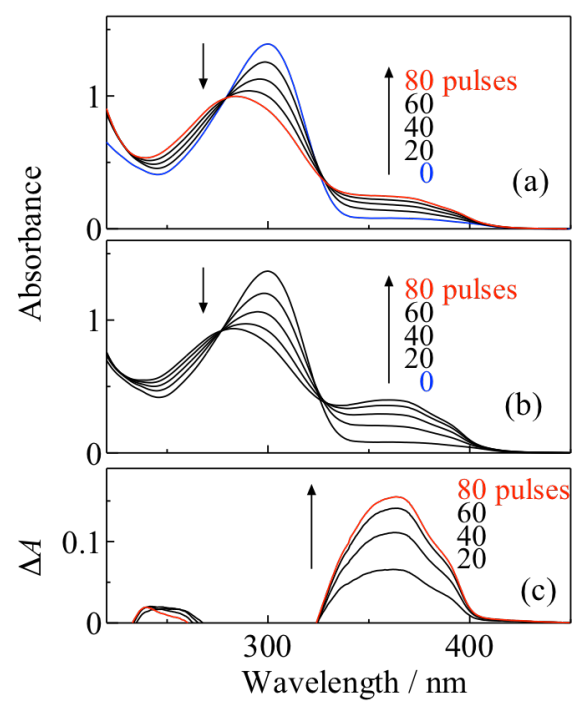

Figure S15. Absorption spectral changes after $308 \mathrm{~nm}$ laser pulsing (a) and $308 \mathrm{~nm}$ plus $50 \mathrm{~ns}$ delayed $440 \mathrm{~nm}$ laser pulsing (b) in the degassed $\mathrm{CH}$ of ClPB@T. (c) Difference absorption spectra between ones in (a) and (b) at the corresponding number of the laser pulses.

\section{DFT calculation for Heat of formation and the schematic configurations of the radicals}

The calculation was carried out at the DFT level, using the Gaussian 09 software package. The geometries of XDK and DKR were fully optimized by using the 6-31G(d) base set at the UB3LYP method. 1 Hartree $=627.5095 \mathrm{kcal} \mathrm{mol}^{-1}$.

Table S1. Calculated heats of formation for XDK.

\begin{tabular}{cc}
\hline $\mathrm{XDK}$ & $\Delta_{\mathrm{f}} H(\mathrm{XDK}) /$ hartree \\
\hline $\mathrm{BrAB}$ & -3571.759521 \\
$\mathrm{ClAB}$ & -1460.245691 \\
$\mathrm{BrPB} @ \mathrm{Ph}$ & -3531.104577 \\
$\mathrm{ClPB} @ \mathrm{Ph}$ & -1419.590798 \\
$\mathrm{BrPB} @ \mathrm{~F}$ & -3528.912714 \\
$\mathrm{ClPB} @ \mathrm{~F}$ & -1417.399767 \\
$\mathrm{BrPB} @ \mathrm{~T}$ & -3851.896107 \\
$\mathrm{ClPB} @ \mathrm{~T}$ & -1740.380837 \\
\hline
\end{tabular}


Table S2. Calculated heats of formation for the radicals produced by dehalogenation.

\begin{tabular}{ccc}
\hline Radical & $\Delta_{\mathrm{f}} H(\mathrm{X}) /$ hartree & $\Delta_{\mathrm{f}} H(\mathrm{DKR}) /$ hartree \\
\hline $\mathrm{Br}$ & -2571.654558 & - \\
$\mathrm{Cl}$ & -460.133882 & - \\
$\mathrm{ABR}$ & - & -1000.013437 \\
$\mathrm{~PB} @ \mathrm{PhR}$ & - & -959.356676 \\
$\mathrm{~PB} @ \mathrm{FR}$ & - & -957.162304 \\
$\mathrm{~PB} @ \mathrm{TR}$ & - & -1280.14775 \\
\hline
\end{tabular}

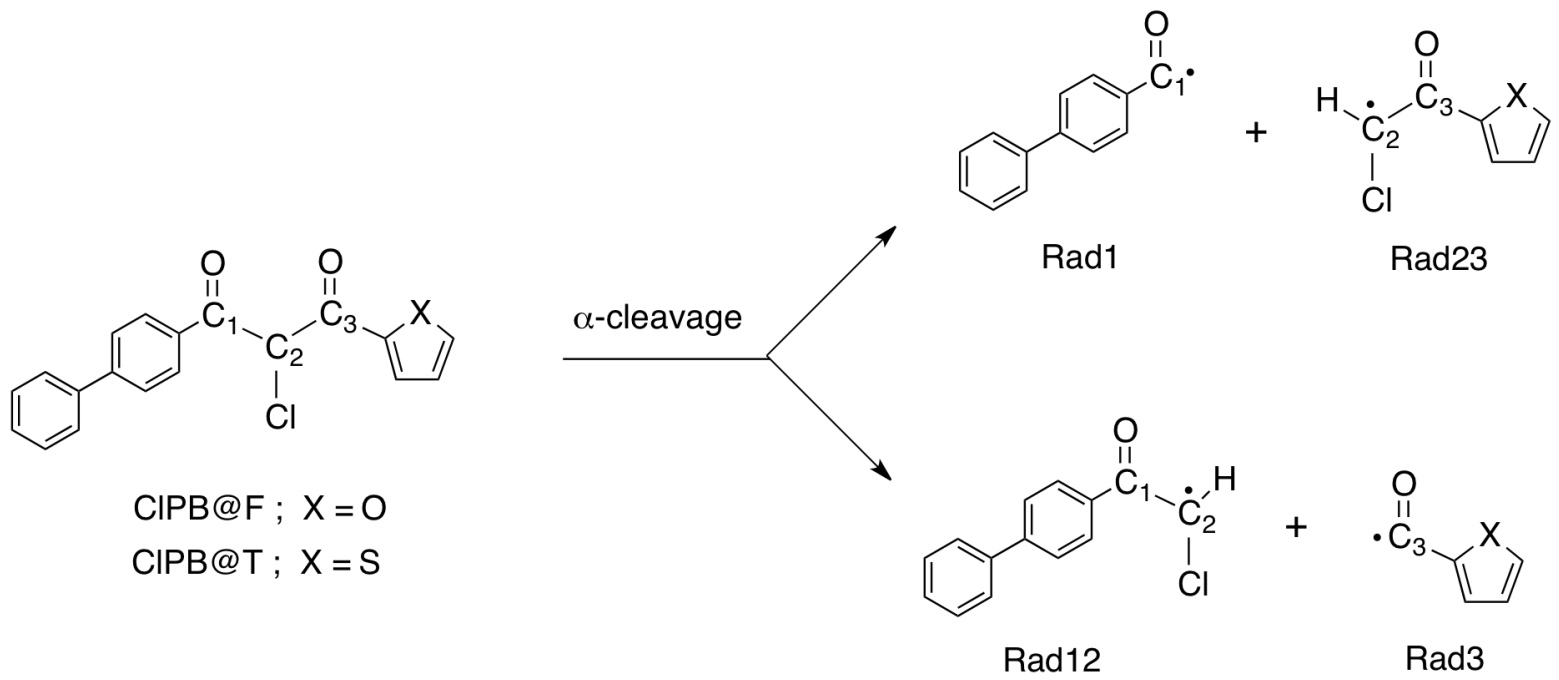

Scheme S1. Possible pathways for of $\alpha$-cleavage in ClPB@F and ClPB@T with numbered carbon atoms.

Table S3. Calculated heats of formation for the radicals produced by $\alpha$-cleavage.

\begin{tabular}{ccccc}
\hline CIDK & $\begin{array}{c}\Delta_{\mathrm{f}} H(\operatorname{Rad} 1) / \\
\text { hartree }\end{array}$ & $\begin{array}{c}\Delta_{\mathrm{f}} H(\operatorname{Rad} 23) / \\
\text { hartree }\end{array}$ & $\begin{array}{c}\Delta_{\mathrm{f}} H(\operatorname{Rad} 12) / \\
\text { hartree }\end{array}$ & $\begin{array}{c}\Delta_{\mathrm{f}} H(\operatorname{Rad} 3) / \\
\text { hartree }\end{array}$ \\
\hline $\mathrm{ClAB}$ & -501.952884 & -958.194274 & -1000.842114 & -459.305718 \\
$\mathrm{ClPB} @ \mathrm{Ph}$ & -575.78773 & -843.707749 & -843.707749 & -344.815564 \\
$\mathrm{CIPB} @ \mathrm{~F}$ & $\uparrow$ & -841.513097 & $\uparrow$ & -342.621252 \\
$\mathrm{CIPB} @ \mathrm{~T}$ & $\uparrow$ & -1164.496754 & $\uparrow$ & -665.496868 \\
\hline
\end{tabular}




\section{Note and Reference}

1. L. Cao, J. Ding, G. Yin, M. Gao, Y. Li and A. Wu, Thioglycoluril as a novel organocatalyst: rapid and efficient $\alpha$-monobromination of 1,3-dicarbonyl compounds, Synlett, 2009, $1445-1448$. 